Thorax (1963), 18, 39

\title{
Benign pleural lesions simulating tumour
}

\author{
L. T IVEN I US
}

From the Lung Clinic, Renström's Hospital, University of Göteborg, Göteborg, Sweden

Without the aid of thoracotomy it is often difficult to establish a diagnosis in cases of tumour in the thorax. Certain forms of benign pleural changes are likely to be misinterpreted as intrapulmonary, and operation for suspected lung tumour may be carried out. In the cases described here, it was possible to establish the diagnosis without employing thoracotomy. As very little attention appears to have been paid to these lesions in the literature, a number of cases recently observed have been collected.

\section{MATERIAL AND RESULTS OF INVESTIGATION}

Details of the 10 patients, nine men and one woman, are given in the Table.

CASE HISTORIES There was nothing to suggest malignant disease in the history of any of these patients. Six came because of bronchitis, combined with haemoptysis in two patients, and two patients had pleurisy. The other two patients were investigated after a routine chest radiograph.

RADIOLOGICAL EXAMINATION The patients' radiographs showed one or more foci suspected of being tumours. Sometimes they appeared as solitary or multiple coin lesions, which were situated peripherally in the lung parenchyma (Fig. 1). In others it was clear from the beginning that the lesions were located in the pleura (Fig. 2) or on the diaphragm (Fig. 3). In all patients, additional radiographs with oblique projections and tomograms, pneumothorax, and thoracoscopy enabled the site of the changes to be located in the pleura (Fig. 4a and b). The lesions were found to be bilateral in half of the cases.

Finally, the diagnosis was verified by pleural biopsy at thoracoscopy. The lesions were far from being always obvious, however. Re-examination of previous films and mass-radiography exposures revealed changes in a number of cases. In some patients changes which were present in the later pictures were not always to be found in the earlier ones, but sometimes an increase in the changes could be observed.

THORACOSCOPY The patients were examined by thoracoscopy, and pleural lesions in the form of scattered plaques were found. These were whitishyellow and slightly raised, up to 2 to $3 \mathrm{~mm}$., with a rough surface and a very distinct line of demarcation between them and an otherwise completely normal pleura. They varied in size from that of confetti to that of the palm of the hand. Occasionally they were also observed on the diaphragm but not on the visceral pleura.

BIOPSY Biopsy from these cartilaginous or bonehard plaques was carried out with forceps. The diagnosis in all cases was fibrous hyaline-sclerotic connective tissue, generally with no trace of inflammation, though in two separate cases there was a certain amount of leucocytic infiltration (Fig. 5) (Zettergren, 1962). In one case at least (Fig. 3) calcareous deposits were seen in the lesion.

OTHER EXAminations Two patients had acute pleurisy, in both cases of undetermined, though

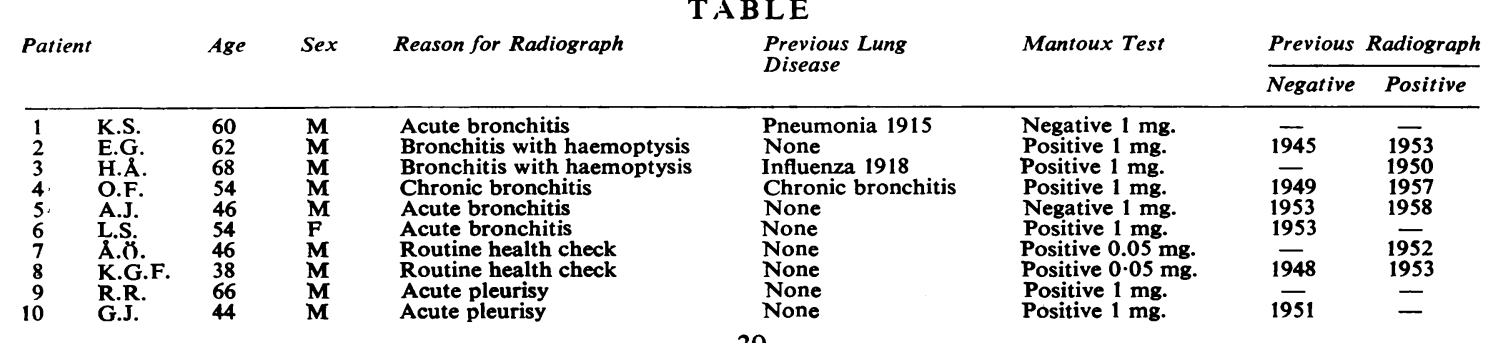




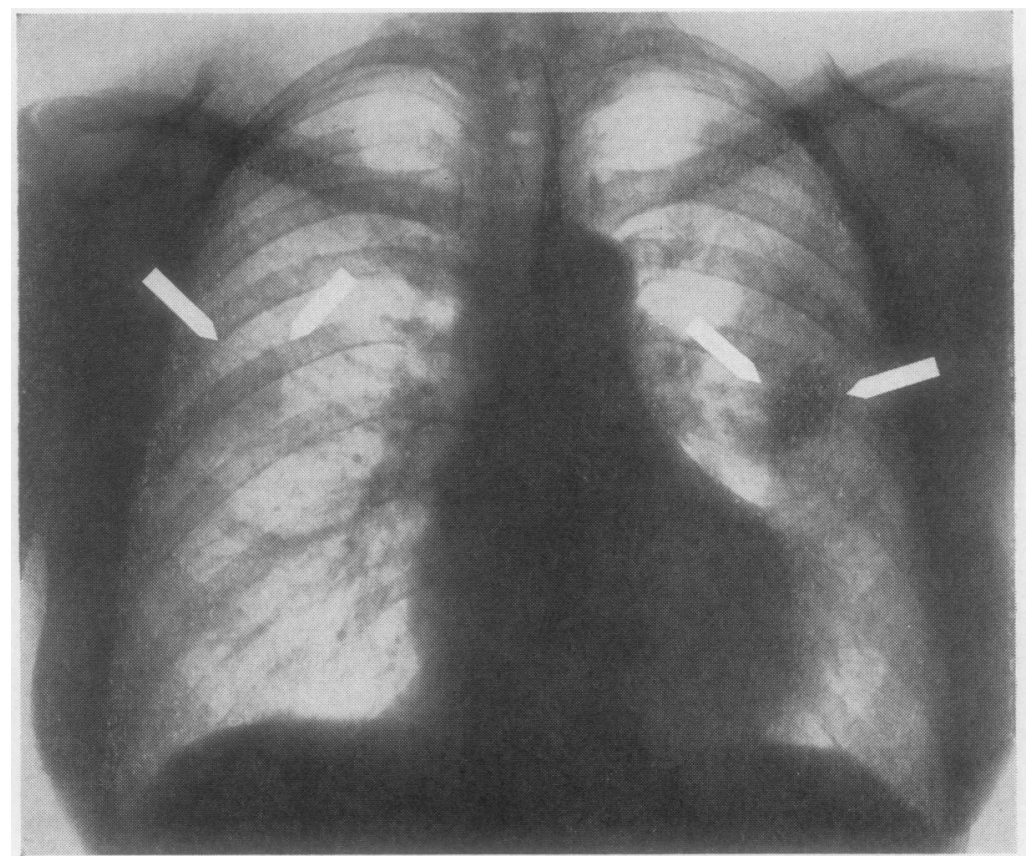

FIG. 1. Bilateral coin lesions mistaken for multiple metastases.

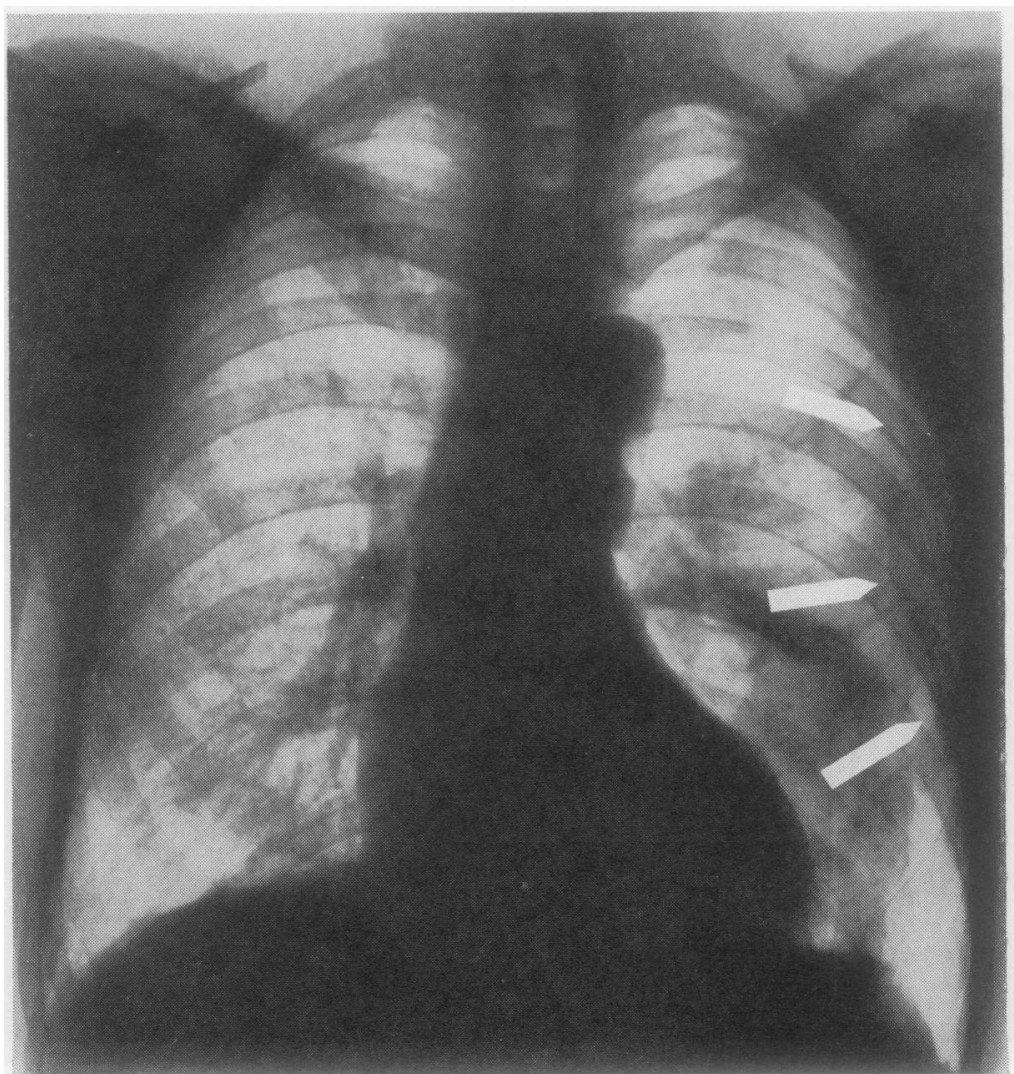

FG. 2. 'Tumour' on the lateral wall of the thorax. Artificial pneumothorax. 


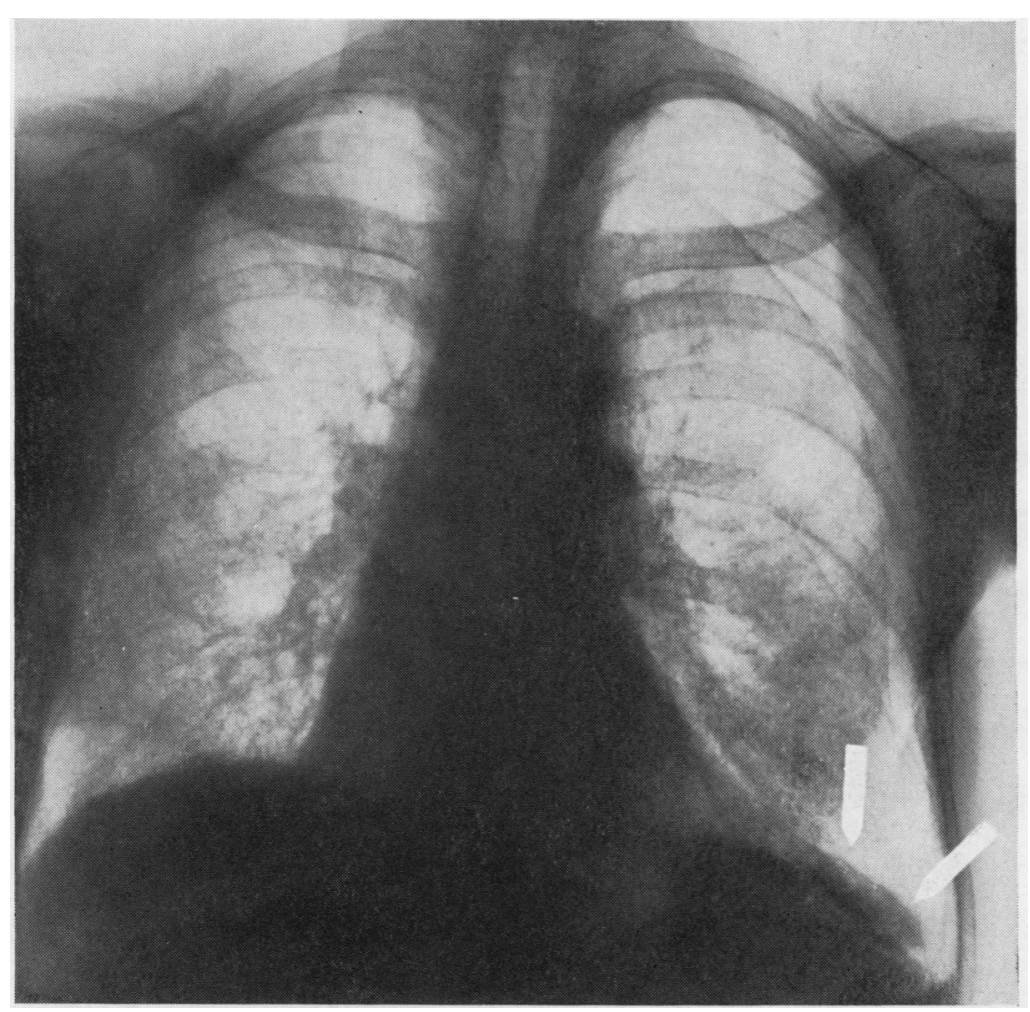

FIG. 3. 'Tumour' with calcifications on the diaphragm. Artificial pneumothorax.

most iikely non-tubercular, origin. The changes found gave the impression of being of longer standing and of having no connexion with the acute pleurisy. In the case histories of the remaining patients there was no suggestion of any pleurisy. No changes typical of tuberculosis could be found in the radiographs. No tubercle bacilli on guineapig inoculation or in cultures could be isolated from the sputum or the pleural fluid, where this was found. The Mantoux test was negative at $1 \mathrm{mg}$. in two cases, and, except for two patients in whom a positive reaction was obtained at $0.05 \mathrm{mg}$., the rest reacted positively at a minimum of $1 \mathrm{mg}$.

\section{DISCUSSION}

INCIDENCE In the fairly extensive literature on tumours of the chest wall there is no mention of the lesions described here. As is shown by this investigation, however, they are probably not so very uncommon, and they must be borne in mind when a differential diagnosis is being made. In necropsy material these changes are met with now and again, most often on the parietal pleura, but also on the visceral pleura (Zettergren, 1962).
DIAGNOSIS When a turnour, possibly a malignant one, was suspected on the evidence of a chest radiograph, thoracoscopy often brought reassurance. The changes had a benign appearance, with a sharply defined outline on a pleura otherwise free from irritation. On the other hand, their extent was often much greater than would be suspected from the film, because a plaque must be of a certain thickness before it is apparent on a film. The changes were situated entirely on the parietal pleura and occasionally on the diaphragm. At times they lay like a string of beads parallel with the line of the ribs.

Without the use of thoracoscopy (Jacobaeus, 1916) the diagnosis must be difficult to establish. Tomography, it is true, revealed the changes situated on the pleura or in the periphery of the lung, and when pneumothorax was applied the changes were easily located in the wall of the thorax. It should be possible to reach a diagnosis by means of incision under fluoroscopy with needle biopsy (Donohoe, Katz, and Matthews, 1948 ; DeFrancis, Klosk, and Albano, 1955; Abrams, 1958 ; Mosbech, Kristensen, Pallesen, and Viskum, 1960), but with the comparatively 


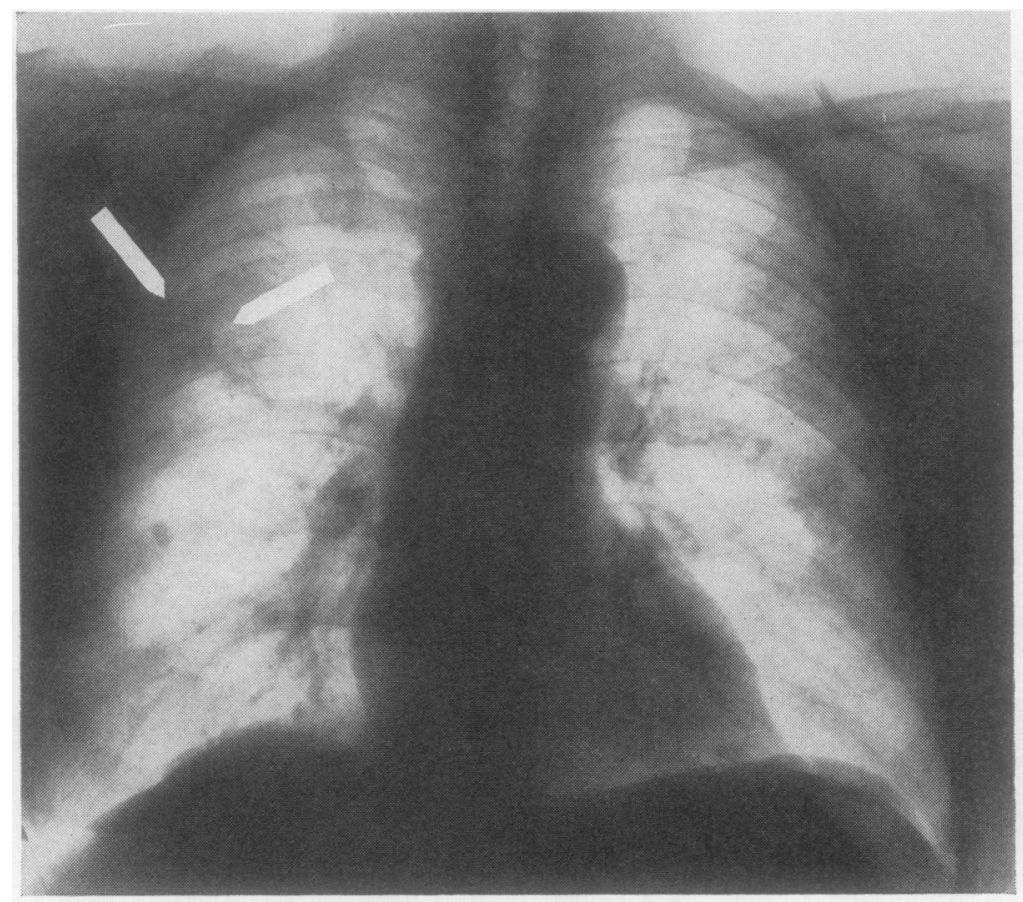
shown on tomograms. 


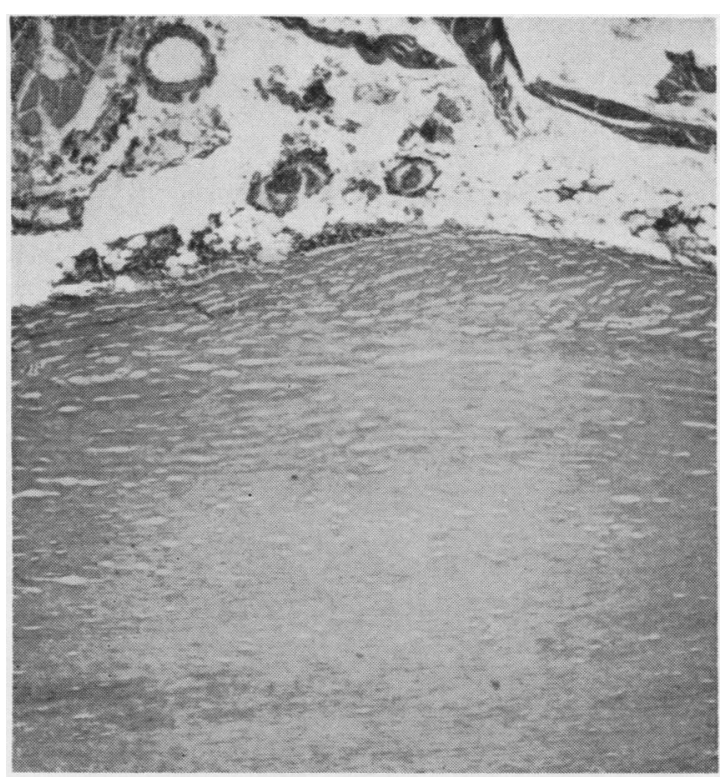

FIG. 5. Biopsy material showing fibrous hyaline-sclerotic connective tissue.

slight operation of thoracoscopy a more certain diagnosis is obtained. In this way there is no need for thoracotomy.

DIFFERENTIAL DIAGNOSIS A very similar radiographic and clinical appearance is given by the lipomatous accumulations in the pleura described by various authors (Lauche, 1928 ; Neugebauer, 1936 ; Evander, 1948 ; Ten Eyck, 1960). Even on thoracoscopy such changes may have the same appearance and distribution as those in our patients. Their origin is undetermined. It has been argued that they may occur by way of reaction to an inflammatory process (Brandt, 1926 ; Evander, 1948), but such changes are found in patients who are completely normal and even in newborn babies (Neugebauer, 1936). In these cases, however, the microscopical findings are quite different from those in our own cases.

The pleural shadows that went by the name of 'lamellar pleurisy' (Fleischner, 1927) were interpreted as being caused by an infectious process. but an appearance of this kind may also be due to the shadows of normal soft parts (Neugebauer, 1936 ; Kubat, 1936). The normal layer of muscle on the inside of the ribs may produce a similar appearance (Knutsson, 1932).

Calcareous deposits in the pleura are described as a condition remaining after tuberculous pleurisy, empyema, and thoracic injuries followed by haemothorax (Head, 1934 ; Boswell and Dredge, 1940 ; Jarniou, Moreau, Garrigou, and Clément, 1959). Plaques with calcareous incrustation have also been described in silicosis (Lommel, 1939) and in other pneumoconioses, and when they are situated in the basal pleura and the diaphragm are regarded as almost pathognomonic of asbestosis. They have also been observed in the lungs of workers in the talc industries (Siegal, Ross Smith, and Greenburg, 1943) and even in the lungs of persons exposed to other kinds of dust (Ross Smith, 1952). Calcareous deposits are considered to be secondary to a pleural irritation resulting from trauma, infection, or chemical effect caused by the foreign material in question. In the cases discussed in this paper, where there were in fact no pronounced calcareous deposits, no evidence of any such exposure to a foreign material could be found in any of the patients.

AETIOLOGY AND PATHOgEnEsis The lesions referred to are mentioned in the morbid anatomical literature (Lauche, 1928). They are described as scattered, white, thickened patches, sometimes coralliform, consisting of hard fibrous hyaline connective tissue which may contain bony tissue, and in which diffuse calcification and sooty pigmentation may also be shown. These changes have also been repeatedly observed at thoracotomy (Bergh, 1962), but in that event the radiograph has given no preliminary warning of their existence, and they have been purely accidental findings.

The same patho-anatomical character is revealed by the round or oval free bodies sometimes found in the thoracic and abdominal cavities (Reid, 1836 ; Hoche, 1910 ; Klinkowstein and Belajewa, 1926 ; Neumann, 1930). These free bodies, which are common in old pneumothorax cavities, are formed by the movements of the lung and may possibly owe their origin to accumulations of fibrin around a nucleus of cells detached from endothelial or lymphoid tissue. It is also suggested (Davies, 1930) that the origin might be a bleeding from injury to the lung or from puncture of an intercostal vessel by a needle. Another author (Pollak, 1930) says, however, with emphasis that these free bodies must be a result of a pleural effusion and not of bleeding.

Only suppositions can be put forward as to the origins of the changes dealt with here. It seems likely that the condition is a residual one, following on a pleurisy or some form of irritation which affected the pleura, side by side with the mechanism giving rise to the free bodies we have 
mentioned. Apart from the two patients who had acute pleurisy, however, none of the case histories suggested any pleurisy. Often bilateral changes were found, and it is improbable that none of the patients would have noticed such extensive disease, even if a pleurisy may occasionally pass without leaving many traces behind or at least may be forgotten by the patient after the lapse of many years. All the patients stated that their lungs had previously been healthy on the whole. Extensive adherence between the pleural layers was present in several patients, which must be interpreted as a sign of a pleural irritation. None of these patients ever had any trauma to the thorax and none had ever been punctured in the pleura. That bleeding could be the origin seems less probable.

Even if the origin of these changes is obscure, it is in any event clear that here is a benign complaint, which is not at all uncommon, and which must be kept in mind in all cases of obscure lung changes where tumour is suspected.

\section{SUMMARY}

An account is given of 10 patients with benign pleural changes consisting of hyaline sclerotic fibrin. The changes had at first been misinterpreted as lung or pleural tumours. The diagnosis was established with the aid of radiographs including tomography, pneumothorax, and thoracoscopy.

\section{REFERENCES}

Abrams, L. D. (1958). Lancet, 1, 30.

Bergh, N. P. (1962). Personal communication.

Boswell, J. R., and Dredge, T. E. (1940). Med. Bull. Veterans' Adm. (Wash.), 17, 75.

Brandt, M. (1926). Beitr. path. Anat., 76, 133.

Davies, H. M. (1930). Surgery of the Lung and Pleura, p. 234. Oxford University Press, London.

DeFrancis, N., Klosk, E., and Albano, E. (1955). New Engl. J. Med., 252,948 .

Donohoe, R., Katz, S., and Matthews, M. (1948). Ann. intern. Med.,

48, 334. Evander, L. C. (1948). Amer. Rev. Tuberc., 57, 495.

Fleischner, F. (1927). Fortsch. Röntgenstr., 36, 319.

Head, J. (1934). Ann. intern. Med., 7, 1295.

Hoche, L. (1910). Arch. Mid. exp., $22,507$.

Jacobaeus, H. C. (1916), Beitr. Klin. Tuberk., 35, 1

Jarniou, A. P., Moreau, A., Garrigou, J., and Clément (1959). Sem. Hốp. Paris, 35, 375.

Klinkowstein, J., and Belajewa, N. (1926). Beitr. Klin. Tuberk., 63, 313.

Knutsson, F. (1932). Acta radiol. (Stockh.), 13, 638.

Kubat, A. (1936). Fortschr. Röntgenstr., 53, 53.

Lauche, A (1928). In Handbuch des speziellen pathologischen Anatomic und Histologie, ed. F. Henke and $O$. Lubarsch, band 3, teil 1 , und Histologie, ed. F. Hent
p. 869 . Springer, Berlin.

Lommel, F. (1939). Dtsch. med. Wschr., 65, 871.

Mosbech, J., Kristensen, H. P Ø., Pallesen, A. E., and Viskum, P. (1960). Nord. Med., 63, 558.

Neugebauer, W. (1936). Fortschr. Röntgenstr, 53, 61.

Neumann, W. (1930). Die Klinik der Tuberkulose Erwachsener, 2nd ed.

p. 466. Springer, Vienna.
Pollak, S. (1930). Beitr. Klin. Tuberk., 74, 494.

Reid, J. (1836). Edinb. Med. Surg. J., 3,893 (cited from Lauche).

Siegal, W., Smith, A. Ros', and Greenburg, L. (1943). Amer. J. Roentgenol., 49, 11.

Smith, A. Ross (1952). lbid., 67, 375

Ten Eyck, E. A. (1960). Radiology, 74, 295.

Zettergren, L. (1962). Personal communication. 